\title{
Genetic structure of a linear population of Beta vulgaris ssp. maritima (sea beet) revealed by isozyme and RFLP analysis
}

\author{
A. F. RAYBOULD*, J. GOUDET † , R. J. MOGG, C. J. GLIDDON† \& A. J. GRAY \\ Institute of Terrestrial Ecology, Furzebrook Research Station, Wareham, Dorset BH20 5AS and \\ †School of Biological Sciences, University of Wales, Bangor LL57 2UW, U.K.
}

\begin{abstract}
Knowledge of the genetic structure of plant populations is necessary for the understanding of the dynamics of major ecological processes. It also has applications in conservation biology and risk assessment for genetically modified crops. This paper reports the genetic structure of a linear population of sea beet, Beta vulgaris ssp. maritima (the wild relative of sugar beet), on Furzey Island, Poole Harbour. The relative spatial positions of the plants were accurately mapped and the plants were scored for variation at isozyme and RFLP loci. Structure was analysed by repeated subdivision of the population to find the average size of a randomly mating group. Estimates of $F_{\mathrm{ST}}$ between randomly mating units were then made, and gave patterns consistent with the structure of the population being determined largely by founder effects. The implications of these results for the monitoring of transgene spread in wild sea beet populations are discussed.
\end{abstract}

Keywords: $F$-statistics, gene flow, isozymes, RFLPs.

\section{Introduction}

Knowledge of the genetic structure of populations is vital for a thorough understanding of the dynamics of major ecological processes such as colonization, invasion, succession and extinction (e.g. Avise, 1994). It also has important consequences for conservation strategies (Ellstrand \& Elam, 1993) and the efficient sampling of crop genetic resources (e.g. Schoen \& Brown, 1993). Recently, interest in the genetic structure of natural plant populations has increased because of the requirement to predict and monitor the rates of gene flow from genetically modified crops (Gliddon, 1994).

In the UK, one species pair where gene flow could occur between the transgenic crop and a natural population is sugar beet (Beta vulgaris L. ssp. vulgaris) and wild sea beet (Beta vulgaris L. ssp. maritima (L.) Arcang. (= Beta maritima L.; Raybould \& Gray, 1993). Although evidence for

\footnotetext{
${ }^{*}$ Correspondence.

$\ddagger$ Present address: Institut de Zoologie et d'Ecologie Animale, Bâtiment de Biologie, Université de Lausanne, CH-1015, Switzerland.
}

gene flow between cultivated and wild beet in the UK is largely anecdotal (e.g. Hornsey \& Arnold, 1979; Evans \& Weir, 1981), gene flow has been shown to occur in the sugar beet seed-producing areas of southern France (Santoni \& Bervillé, 1992; Boudry et al., 1993). This paper examines the genetic structure of a wild beet population to assess how genes might spread following transfer from a genetically modified beet.

The spatial position of wild beet plants on two transects on Furzey Island, Poole Harbour (UK), were accurately mapped. Plants were then analysed for variation at RFLP and isozyme loci. The two classes of marker were used to maximize the number of variable loci and to allow comparison of the amounts of variation detected by each class. The analytical methods are based on a logical extension of Weir \& Cockerham's (1984) formulation of Wright's $F$-statistics as described by Goudet $e t$ al. (1994). They emphasize the often overlooked concept that $F_{\mathrm{ST}}$ should be determined between randomly mating groups. Therefore we adopt the approach of repeatedly subdividing the population until no substructure can be detected within groups (i.e. the mean $F_{\text {IS }}$ is zero). We then calculate $F_{\text {ST }}$ 
values between such groups. The $F_{\mathrm{ST}}$ values between all pairs of randomly mating groups are presented in a matrix so that the structure of the population can be visualized easily.

\section{Materials and methods}

\section{Collection of tissue}

Tissue (4-5 leaves) from 220 Beta vulgaris ssp. maritima plants was collected from Furzey Island, Poole Harbour, UK, during the summer of 1993. The plants occurred on the drift-line on the south-east/ east (plants 1-170) and north coasts (plants 171-220) of the island (Fig. 1). The relative positions of all the plants were determined and used to subdivide the population when calculating the degree of substructure. All plants were hermaphrodite (cf. some gynodioecious populations in France).

\section{Isozyme electrophoresis}

Leaf material was used directly after collection, or stored for up to 3 days at $4^{\circ} \mathrm{C}$. Protein extracts were prepared from $1 \mathrm{~g}$ tissue with $3 \mathrm{~mL}$ of extraction buffer and were run on polyacrylamide gels. Sample preparation, gel buffers and running conditions were as described by Raybould et al. (1991), except that in the extraction buffer 2 per cent caffeine replaced polyvinylpolypyrrolidone (PVPP) and the concentration of mercaptoethanol was 1 per cent. Gels were stained following Shaw \& Prasad (1970) as modified by Raybould et al. (1991).

\section{RFLP analysis}

Leaf tissue was ground to a fine powder in liquid nitrogen and stored at $-70^{\circ} \mathrm{C}$ before use. DNA was obtained from all plants using the method of Dellaporta et al. (1983) with $1 \mathrm{~g}$ of powdered tissue and $15^{\prime} \mathrm{mL}$ of extraction buffer. The DNA yield was not quantified but appeared consistent between plants and was sufficient for two restriction digests.

Beta DNA was digested with Bam $\mathrm{HI}$ and run on 0.8 per cent agarose gels buffered with $1 \times \mathrm{TAE}$ at $45 \mathrm{~mA}$ for $16 \mathrm{~h}$. DNA was transferred to Hybond $\mathrm{N}^{+}$membranes (Amersham International plc) using a Hybaid Vacuaid gel blotter.

Probes for RFLP analysis were cDNA clones prepared from either leaves (L prefix) or roots $(\mathrm{R}$ prefix) of a Polish sugar beet line (Ramsden, 1991). These probes were known to have low copy number and were polymorphic in a segregating $F_{2}$ family of sugar beet. No linkage was detected between any of the probes for which full data sets were available (Ramsden, 1991).

Probe DNA was labelled using ${ }^{32} \mathrm{P}$ dCTP and the Ready-to-Go kit supplied by Pharmacia Biosystems. Unincorporated nucleotides were removed with NICK spin columns (Pharmacia). Probes were hybridized to the filters in a Hybaid mini-hybridization oven using the protocol of Magrath et al. (1994).

\section{Statistical methods}

The genetic structure of the Furzey population was analysed using loci at which the commonest allele had a frequency of below 0.95 . The analysis was essentially the derivation of all pairwise genetic distances between the separate randomly mating units comprising the transects.

To find the size of a random breeding unit, transect 1 was repeatedly subdivided (by inspection of the plants' spatial distribution) into well-defined groups of roughly equal size and number of plants.

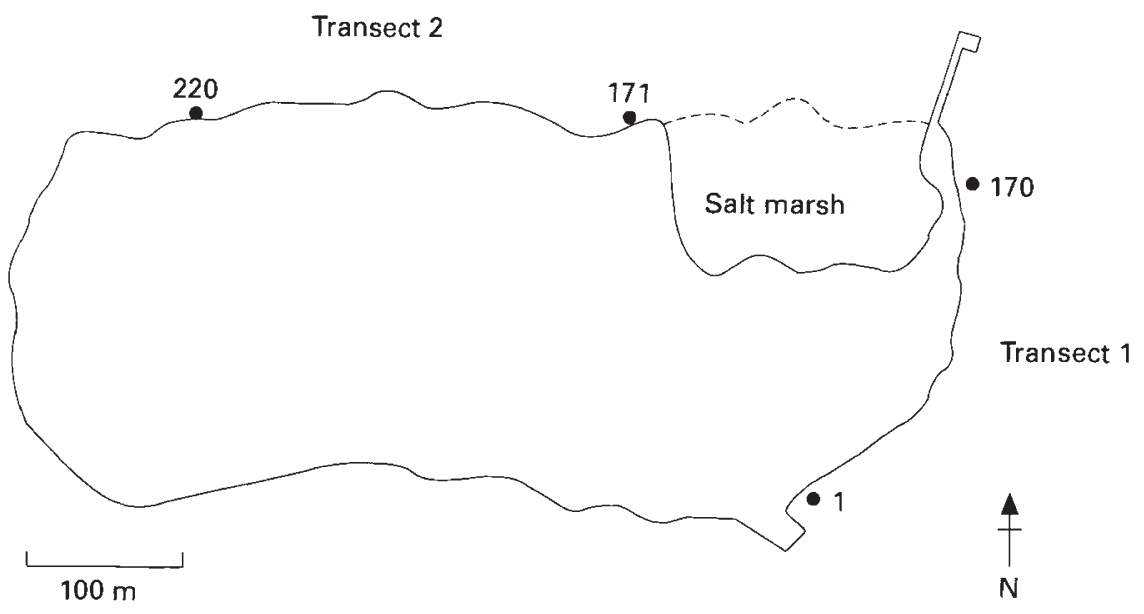

Fig. 1 Location of the transects of sea beet on Furzey Island, Poole Harbour, Dorset. 
The number of groups at each successive stage of subdivision was $2,4,6,10$ and 15 . The mean group $F_{\text {IS }}$ for each stage was calculated for each locus using FSTAT (Goudet, in press), a program which calculates Weir \& Cockerham's (1984) unbiased estimators of $F$-statistics. Confidence intervals were estimated by jackknifing over samples (when the transect was divided into six or more groups). Only transect 1 data were used as there were insufficient plants in transect 2 to carry out a suitable subdivision procedure. Only loci which showed a strictly monotonic decrease in $F_{\text {IS }}$ with increased population subdivision were assumed to be selectively neutral and retained for calculations of over all loci $F_{\text {IS }}$ and $F_{\mathrm{ST}}$ values (Goudet et al., 1994).

The mean over all loci values of $F_{\text {IS }}$ at each subdivision stage were obtained, with confidence intervals estimated from jackknifing over loci. The average size of a randomly mating unit was identified as the largest group size in which $F_{\text {IS }}$ was not significantly different from zero. This group size (henceforth a 'patch') was then used in calculations of genetic distances by deriving $F_{\mathrm{ST}}$ between each pair of patches. In this analysis transect 2 was considered to be comprised of patches of roughly equal size to those identified in transect 1.

\section{Results}

\section{Characterization of isozyme loci}

Beet plants were examined for 13 isozyme systems which detected approximately 30 loci (Gray et al., 1994). Genetically interpretable variation was found at seven loci, acid phosphatase $\left(A c P H^{2}\right)$, glutamicoxaloacetic transaminase $\left(G O T^{3}\right.$ and $\left.G O T^{4}\right)$, malic enzyme $\left(M E^{2}\right)$, 6-phosphogluconate dehydrogenase $\left(6 P G D H^{2}\right)$, phosphoglucose isomerase $\left(P G I^{2}\right)$ and shikimic acid dehydrogenase $(S k D H)$. Superscripts represent zones of activity away from the origin. No formal genetic analysis was performed; however, our interpretations of banding patterns agreed with those of other authors working with isozyme variation in sugar beet (e.g. van Geyt \& Smed, 1984; Abe \& Tsuda, 1987; Nagamine et al., 1989; Aicher \& Saunders 1990).

The proportion of polymorphic loci was 0.233 and the average number of alleles per locus 1.400 . Across all polymorphic loci the mean observed heterozygosity $\left(H_{0}\right.$ was 0.157 and the mean Nei's diversity index $\left(H_{\mathrm{t}} ; \mathrm{Nei}, 1987\right.$, p. 164) was 0.228 .

\section{Characterization of RFLP loci}

The plants were screened with 19 single or low copy number sugar beet cDNA probes (Ramsden, 1991). These probes revealed approximately 31 loci. Of these, seven probes (L3, L5, L9, R1, R4, R7 and $\mathrm{R} 13)$ showed variation consistent with that at a single locus.

The proportion of polymorphic loci and the number of alleles per locus were very similar to the isozyme loci being, respectively, 0.225 and 1.355 . The mean $H_{0}$ was 0.256 and the mean $H_{\mathrm{t}}$ was 0.299 . Neither was significantly different from the value for isozyme loci $\left(H_{0}: t_{12}=0.85 ; H_{\mathrm{t}}: t_{12}=0.57\right.$; seven polymorphic loci in each class).

\section{Population substructure and gene flow}

Individual loci. All calculations of $F_{\text {IS }}$ were made from transect 1 data because of the limited number of plants in transect 2 . Figure 2 shows the pattern of change of $F_{\mathrm{IS}}$ with subdivision stage for the six sufficiently polymorphic loci. $F_{\text {Is }}$ estimates for loci $G O T^{3}$, $M E^{2}, R 4$ and $L 9$ decrease monotonically with smaller group sizes. This is expected if stochastic processes are determining the distribution of genotypes at these loci. $A c P H^{2}$ and $L 3$, on the other hand, show constant values of $F_{\text {IS }}$ at all stages of subdivision. Possible reasons for these results are heterozygote disadvantage at $A c P H^{2}$ and heterozygote advantage or linkage to a self-incompatibility locus at $L 3$.

Over all loci. Mean $F_{\text {Is }}$ values, with confidence intervals derived by jackknifing over loci, were calculated from all loci showing monotonic decrease of $F_{\text {IS }}$ with group size (Fig. 3 ). When the transect is divided into 15 groups, $F_{\text {IS }}$ becomes not significantly different from zero, that is patches of about 11-12 neighbouring plants are behaving effectively as randomly mating units. However, as a population is repeatedly subdivided, the confidence limits of $F_{\mathrm{IS}}$ tend to become wider as the mean is estimated from samples which are smaller and inherently more variable (although there are more of them). Also as the group size reduces, more samples become invariant at a particular locus. Under these conditions, $F_{\text {IS }}$ is undefined at that locus and the sample must be excluded from the analysis. For these reasons there is a greater tendency to wrongly accept the null hypothesis that $F_{\mathrm{IS}}=0$ (i.e. a Type II error) as the group size diminishes. The patch size of 11-12 should, therefore, be regarded as the maximum size of a randomly mating unit. 
The genetic structure of the Furzey beet population was then examined by calculating all pairwise $F_{\mathrm{ST}}$ values between these patches. Transect 2 was included in the analysis by dividing it into five patches of a size roughly equal to those of transect 1. These results are displayed in Fig. 4. It is clear that there is no simple relationship connecting $F_{\mathrm{ST}}$ values and the distance between patches. With strict isolation by distance arising from limited pollen and seed flow one would expect $F_{\mathrm{ST}}$ to increase as the distance between patches increases. In Fig. 4 this would be represented by a smooth transition from light to dark squares on moving away from the bottom left to top right diagonal. In transect 1 there is a high degree of relatedness (low $F_{\mathrm{ST}}$ ) between patches 3 to 8 and also between these patches and patches 14 and 15 . There are also regions where neighbouring patches have low relatedness (high $\left.F_{\mathrm{ST}}\right)$, for example patches 7 and 8 with patches 9 to 11. In transect 2 there are clearly two groups, 16-18 and $19-20$, where there is high relatedness between patches within each group but lower relatedness between patches in different groups.

Figure 4 also shows that the highest $F_{\mathrm{ST}}$ values are those between patches in different transects. $F_{\mathrm{ST}}$ is a measure of genetic distance between panmictic populations and as such will be influenced by gene flow both in terms of exchange of genes during sexual reproduction and also where individuals share common ancestors; that is, $F_{\mathrm{ST}}$ can be regarded as a measure of genetic similarity through mating or parenthood. In classical isolation by distance models, where gene flow is considered solely in terms of gene exchange during mating, the value of $F_{\mathrm{ST}}$ will increase with greater geographical distance between samples. Deviations from this expectation (such as within transects) can result from a number of factors including localized selection or founder effects.

To test for isolation by distance effects and effects of founders, a partial Mantel test (Manly, 1991) was carried out, partially regressing the matrix of $F_{\text {ST }}^{\text {. }}$ (genetic distances) between pairs of patches on the

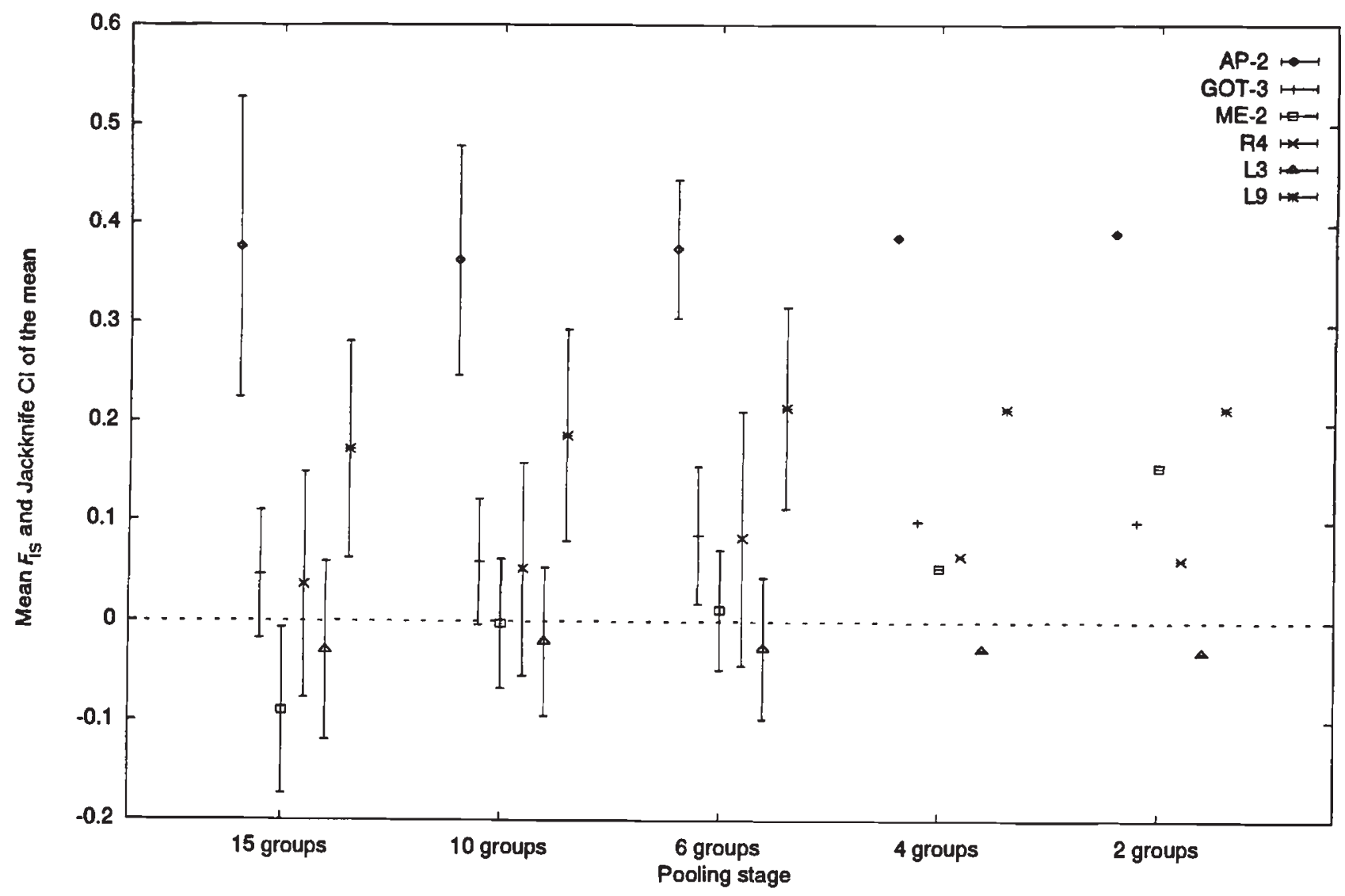

Fig. 2 Per locus changes in $F_{\text {IS }}$ of sea beet with pooling stage along transect 1 on Furzey Island. Note that $F_{\text {IS }}$ values for $G O T^{3}, M E^{2}, L 9$ and $R 4$ increase monotonically with increased pooling. Confidence intervals were estimated by jackknifing over samples. Approximate group sizes: 15 groups, 11 plants; 10 groups, 17 plants; 6 groups, 28 plants; 4 groups, 42 plants; 2 groups, 85 plants. 
geographical distances between those patches and a matrix distinguishing distances between patches within a single transect from those between patches in different transects. The probability of obtaining the partial regression coefficients for the effects of geographical distance and transect membership were tested using a randomization process (Manly, 1991). The partial regression of $F_{\mathrm{ST}}$ on geographical distance (transect effect removed) was nonsignificant $(b=0.278, P \approx 0.1025)$, whereas the partial regression of $F_{\mathrm{ST}}$ on transect membership was highly significant $(b=0.661, P<0.0001)$, that is, pairwise $F_{\text {ST }}$ values were significantly lower between patches in the same transect than between patches in different transects after the effects of geographical distance were removed. This evidence strongly suggests that genetic distance measured as $F_{\mathrm{ST}}$ between patches of beet on Furzey Island is determined primarily by whether groups of plants come from the same or different transects.

\section{Discussion \\ Comparison of isozymes and RFLPS}

For all measures of genetic variation and genetic substructure RFLPs did not differ significantly from isozymes. It has been suggested (e.g. by Clegg, 1989) that RFLPs should reveal more alleles per locus and have a higher proportion of polymorphic loci than isozymes. This was found not to be the case in our sample of 31 RFLP and 30 isozyme loci. The same result was observed in Hordeum vulgare by Zhang et al. (1993). Observed heterozygosity $\left(H_{0}\right)$ and genetic diversity $\left(H_{t}\right)$ were not significantly different between isozymes and RFLPs for the seven polymorphic loci of each class. Zhang et al. (1993) found that in $H$. vulgare RFLPs had significantly higher $H_{\mathrm{t}}$ but similar $H_{0}$ to isozymes. More studies are clearly needed to establish whether this is a general phenomenon. There was no evidence that RFLPs were

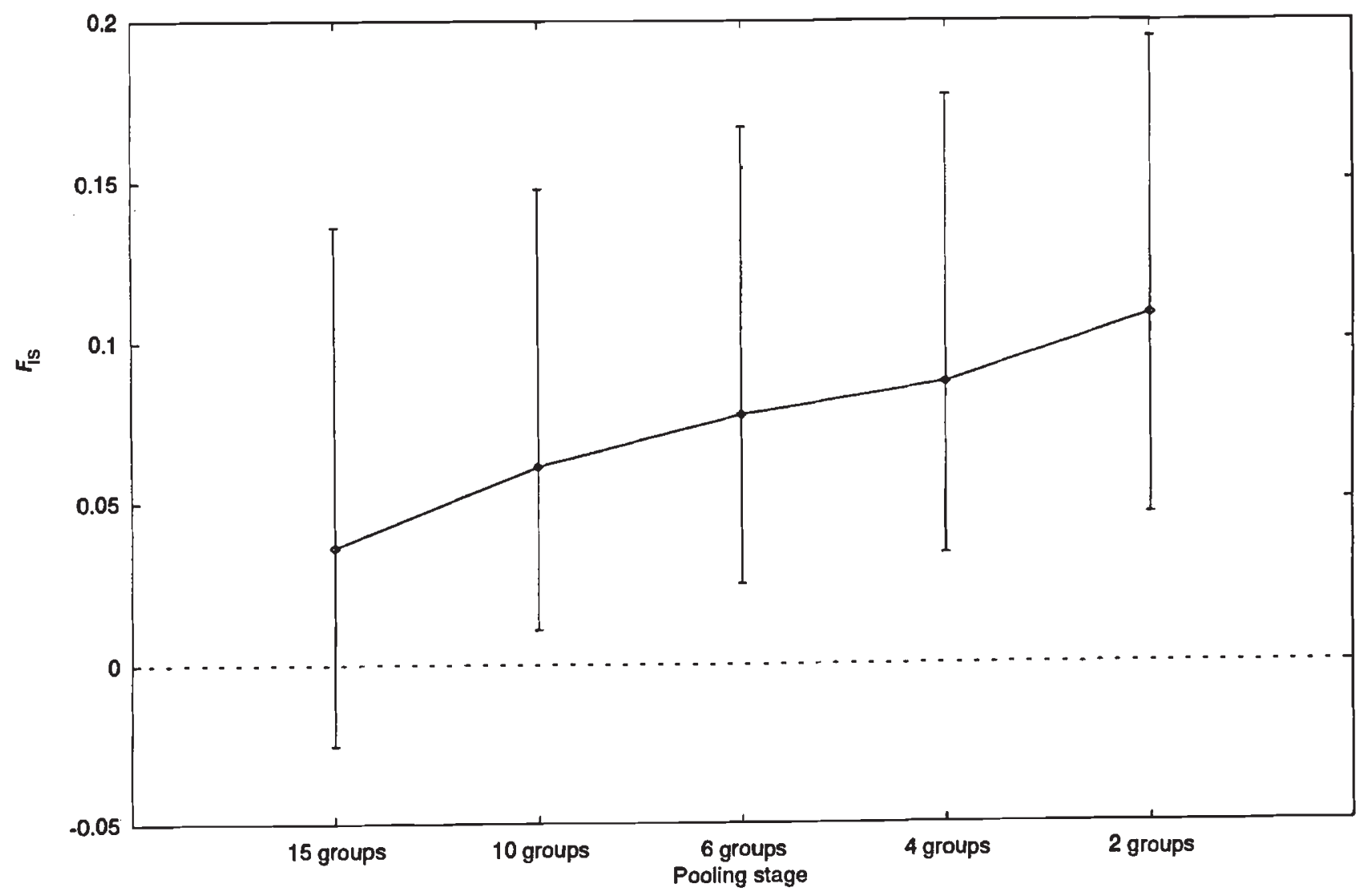

Fig. 3 Over all loci changes in $F_{\text {IS }}$ of sea beet with pooling stage along transect 1 on Furzey Island. Confidence intervals were estimated by jackknifing over loci. Pooling strategy as in Fig. 2. 

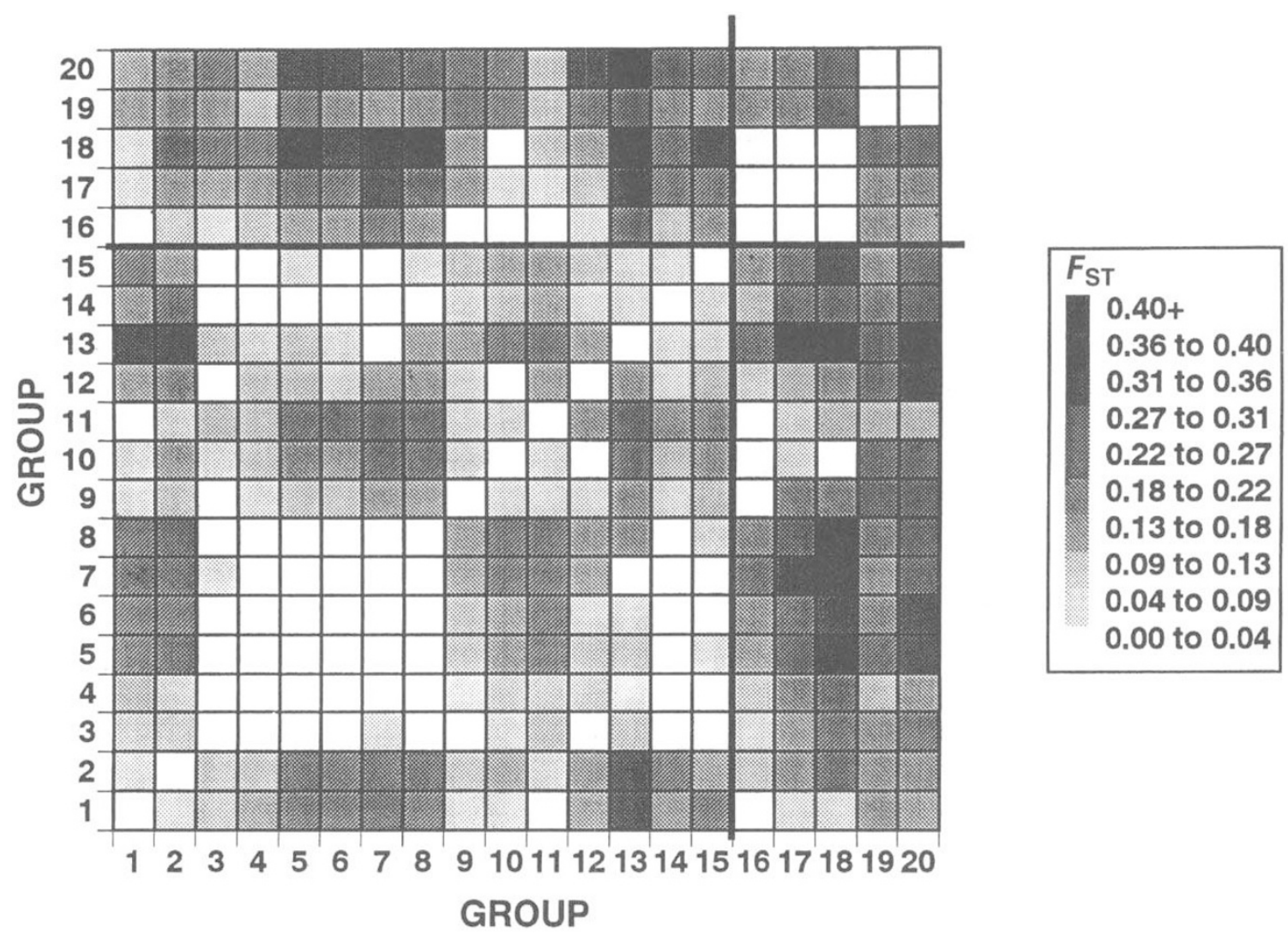

Fig. 4 Diagrammatic representation of $F_{\mathrm{ST}}$ values between pairs of randomly mating patches of sea beet on Furzey Island. Patches 1-15, transect 1; patches 16-20, transect 2.

more or less subject to selection than isozymes, although only three loci of each class were available for analysis.

\section{Genetic structure of wild beet}

Figure 4 shows that the highest $F_{\mathrm{ST}}$ values were found between patches in different transects. A partial Mantel test indicated that this effect resulted from transect membership rather than geographical distance. The relative similarity within transects may be accounted for most easily if the two transects were founded independently by migrants with different genotype frequencies. This also suggests a reason for the pattern of $F_{\mathrm{ST}}$ values within transects shown in Fig. 4. Groups of patches with low $F_{\text {ST }}$ (such as 3-8 in transect 1) may represent the descendants of a very limited subset of the original founders. Patches distant from this group, but with high relatedness to it, could also have arisen from these plants by long-distance seed transport. The occurrence of neighbouring groups between which $F_{\mathrm{ST}}$ is relatively high may result from extinction and subsequent (re)colonization by unrelated migrants.
Taken together the high $F_{\text {ST }}$ value between transects (independent of distance) and the patchiness within transects provide powerful evidence that the genetic structure of beet at this scale is predominantly determined by founder effects rather than limited gene flow resulting from isolation by distance.

The between and within transect results suggest a metapopulation structure for driftline beet populations with continuous extinction and recolonization of patches by a small number of founders (the 'blinking lights' model of Levins, 1970). Extinction of beet patches may be a regular event on Furzey because of cliff falls and storms. The pattern of variation suggests that recolonization occurs from small numbers of individuals and work on the seedling demography of beet in Poole Harbour will attempt to confirm this.

Long-distance seed dispersal, coupled with founder effects mean that if transgenes were transferred to wild beet, the frequency of the transgene would not necessarily decline as a function of distance from the release site. Local populations with a high transgene frequency could be established some distance away and be separated from the 
release site by populations not possessing the gene. Therefore, if it is thought necessary to monitor transgene spread into wild beet, sampling should be extensive rather than intensively concentrated around the release site.

\section{Acknowledgements}

We thank Simon Ramsden, David Marshall and Ian Mackay for the gift of the Beta cDNA clones, Derek Lydiate and Andrew Sharpe for advice on hybridization protocols and BP Exploration for access to Furzey Island. This work was carried out under Contract PECD/7/8/190 of the Department of the Environment's Genetically Modified Organisms Research Programme. The views expressed in this article are those of the authors and not necessarily those of the Department of the Environment.

\section{References}

ABE, J. AND TSUDA, C. 1987. Genetic analysis for isozyme variation in the section Vulgares, genus Beta. Jap. J. Breeding, 37, 283-261.

AICHER, L. D. AND SAUNDERS, J. W. 1990. Inheritance studies and clonal fingerprinting with isoenzymes in sugarbeet. Crop Sci., 30, 1064-1072.

AVISE, J. C. 1994. Molecular Markers, Natural History and Evolution. Chapman and Hall, New York and London.

BOUDRY, P., MÖRCHEN, M., SAUMITOU-LAPRADE, P., VERNET, P. AND VAN DIJK, H. 1993. The origin and evolution of weed beets: consequences for the breeding and release of herbicide-resistant transgenic sugar beets. Theor. Appl. Genet., 87, 471-478.

CLEGG, M. T. 1989. Molecular diversity in plant populations. In: Brown, A. H. D., Clegg, M. T., Kahler, A. L. and Weir, B. S. (eds) Plant Population Genetics, Breeding, and Genetic Resources, pp. 98-115. Sinauer Associates, Sunderland, MA.

DELLAPORTA, s. L., WOOD, J. AND HICKs, J. B. 1983. A plant DNA minipreparation: version II. Plant Mol. Biol. Rep., 1, 19-21.

Ellstrand, N. C. AND Elam, D. R. 1993. Population genetic consequences of small population size: implications for plant conservation. Ann. Rev. Ecol. Syst., 24, 217-242.

EVANS, A. AND WElR, J. 1981. The evolution of weed beet in sugarbeet crops. Kulturpflanze, 29, 301-310.

GLIDDON, c. J. 1994. The impact of hybrids between genetically modified crop plants and their related species: biological models and theoretical perspectives. Mol. Ecol., 3, 41-44.

GOUDET, J. 1996. Fstat V-1.2: a computer program to calculate F-statistics. J. Hered. (in press).

GOUDET, J., DE MEEÜS, T., DAY, A. J. AND GLIDDON, C. J.
1994. The different levels of population structuring of dogwhelks, Nucella lapillus, along the south Devon coast. In: Beaumont, A. (ed.) Genetics and Evolution of Aquatic Organisms, pp. 81-95. Chapman and Hall, London.

GRAY, A. J., RAYBOULD, A. F., WARMAN, E. A., MOGG, R. J., GLIDDON, C. J. AND GOUDET, J. 1994. Genetically Modified Organisms Research Report: Gene Flow in Natural Populations of Brassica and Beta. The Department of the Environment, London.

HORNSEY, K. G. AND ARNOLD, M. H. 1979. The origins of weed beet. Ann. Appl. Biol., 92, 279-285.

LEVINS, R. 1970. Extinction. Lect. Math. Life Sci., 2, 75-77.

MAGRATH, R., BANO, F., MORGNER, M., PARKIN, 1., SHARPE, A., LISTER, C., DEAN, C., TURNER, J., LYDIATE, D. AND MITHEN, R. 1994. Genetics of aliphatic glucosinolates. I. Side chain elongation in Brassica napus and Arabidopsis thaliana. Heredity, 72, 290-299..

MANLY, B. F. J. 1991. The Statistics of Natural Selection. Chapman and Hall, London.

NAGAMINE, T., CATTY, J. P. AND FORD-LlOYD, B. v. 1989. Phenotypic polymorphism and allele differentiation of isozymes in fodder beet, multigerm sugar beet and monogerm sugar beet. Theor. Appl. Genet., 77, 711-720.

NE1, M. 1987. Molecular Evolutionary Genetics. Columbia University Press, New York.

RAMSDEN, s. C. 1991. The Development of RFLP Markers in Sugar Beet. Ph.D. Thesis. University of Birmingham.

RAYBOULD, A. F. AND GRAY, A. J. 1993. Genetically modified crops and hybridization with wild relatives: a UK perspective. J. Appl. Ecol., 30, 199-219.

RAYBOULD, A. F., GRAY, A. J., LAWRENCE, M. J. AND MARSHAll, D. F. 1991. The evolution of Spartina anglica C. E. Hubbard (Gramineae): origin and genetic variability. Biol. J. Linn. Soc., 43, 111-126.

SANTONI, S. AND BERVILlÉ, A. 1992. Evidence for gene exchanges between sugar beet (Beta vulgaris L.) and wild beets: consequences for transgenic sugar beets. Plant Mol. Biol., 20, 578-560.

SCHOEN, D. J. AND BROWN, A. H. D. 1993. Conservation of allclic richness in wild crop relatives is aided by assessment of genetic markers. Proc. Natl. Acad. Sci. U.S.A., 90, 10623-10627.

SHAW, C. R. AND PRASAD, R. 1970. Starch gel electrophoresis of enzymes - a compilation of recipes. Biochem. Genet., 4, 297-320.

VAN GEYT, J. P. C. F. AND SMED, E. 1984. Polymorphism of some marker enzymes of the sugarbeet (Beta vulgaris L.) investigated by polyacrylamide electrophoresis and starch gel electrophoresis. Z. PflZücht., 92, 295-308.

WEIR, B. S. AND COCKERHAM, c. c. 1984 . Estimating $F$-statistics for the analysis of population structure. Evolution, 38, 1358-1370.

ZHANG, Q., SAGHAl MAROOF, M. A. AND KLEINHOFS, A. 1993. Comparative diversity of RFLPs and isozymes within and among populations of Hordeum vulgare ssp. spontaneum. Genetics, 134, 909-916. 